\title{
Medical management of a child with chronic kidney disease
}

\author{
Chandra Abeysekera ${ }^{1}$ \\ Sri Lanka Journal of Child Health, 2006; 35: 133-8
}

(Key words: management, child, chronic kidney disease)

\section{Introduction}

Kidney damage is defined as structural or functional abnormalities of the kidney with or without decreased glomerular filtration rate (GFR), manifest by either pathological abnormalities or abnormalities in blood or urine tests or imaging studies ${ }^{1,2}$. The term chronic kidney disease (CKD) refers to patients with kidney damage or a GFR less than $60 \mathrm{ml} / \mathrm{min} / 1.73 \mathrm{~m}^{2}$ with or without kidney damage for three months or more. Historically, the evaluation and management of CKD was focused on the diagnosis and treatment of specific kidney diseases and dialysis and transplantation for kidney failure. However, an appropriate action plan for patients with CKD requires complete evaluation and management during the early stages of kidney disease, irrespective of the cause.

\section{Evaluation of patients with $\mathrm{CKD}^{3}$}

Children with CKD should be evaluated to determine the diagnosis, severity, complications, co-morbid conditions and the risk factors resulting in further loss of renal function.

\section{Causes of CKD}

Congenital renal anomalies, which occur more frequently in boys and younger children, are the causes for CKD in a majority of children. These include obstructive uropathy, renal dysplasia or hypoplasia, reflux nephropathy and infantile polycystic kidney disease. Other important aetiologies include hereditary and acquired glomerulo-nephropathies.

\section{Clinical presentation}

The onset of CKD may be silent and its progression insidious with symptoms developing later in its course. It may present to the paediatrician in a variety of ways, which may be related to the primary renal disease or due to the consequences of impaired renal function.

\footnotetext{
${ }^{1}$ Senior Lecturer and Head, Department of Paediatrics, Faculty of Medicine, University of Peradeniya
}

\section{Modes of presentation}

The presenting features of CKD include lethargy, anorexia, pallor, failure to thrive, growth retardation, urinary symptoms (poor stream, incontinence, enuresis and haematuria) urinary tract infection, nephritic and nephrotic syndrome, hypertension, cardiac failure, seizures, rickets and an abdominal mass. Some children are detected on routine antenatal ultrasound scanning or routine screening of siblings in an index case. It may not be clear at presentation whether a child has acute and therefore potentially reversible renal failure or acute on chronic renal failure (CRF). However, priority should be given to a child who requires urgent referral to a specialised unit.

\section{Indications for immediate referral to a specialised unit}

Immediate referral to a specialised unit is indicated if child has hyperkalaemia $(>6 \mathrm{mmol} / \mathrm{l})$, symptomatic electrolyte abnormalities (e.g. hypernatraemia, hyponatraemia, hypocalcaemia and hyperphosphataemia), metabolic acidosis, severe hypertension, pulmonary oedema, anuria or oliguria and altered sensorium with or without seizures.

\section{Features suggestive of acute on chronic renal failure}

In a child presenting with features of acute renal failure, presence of growth retardation, pallor, pigmentation, easy bruising, renal osteodystrophy, family history of renal disease, normocytic normochromic or hypochromic microcytic anaemia, small, asymmetric kidneys with or without abnormalities in the collecting systems, ureters and bladder on ultrasound scanning, is suggestive of an acute on chronic renal disease rather than acute renal failure in a previously healthy kidney.

\section{Specific investigations}

History and examination may provide valuable pointers to the underlying cause for renal failure, but in some this will only be revealed by specific investigations. These include renal ultrasound scan, micturating cystourethrogram, radio-isotope scans (DMSA, DTPA or MAG3), intravenous pyelogram, 
antegrade pressure flow studies, urine microscopy and culture, urine protein:creatinine ratio, serum complement (C3, C4), antinuclear antibodies, anti DNA antibodies, anti GBM antibodies, ANCA and renal biopsy

\section{Assessment of severity}

Severity of CKD is assessed by level of kidney function. Estimation of GFR is the best overall index of level of kidney function. GFR is a predictor of complications and allows proper drug dosing in CKD. GFR may be directly estimated by using the Haycock-Schwartz formula in children.

Haycock - Schwartz formula ${ }^{4}$

$\operatorname{GFR}\left(\mathrm{ml} / \mathrm{min} / 1.73 \mathrm{~m}^{2}\right)=\mathrm{k} \mathrm{x}$ height $(\mathrm{cm})$ serum creatinine $(\mathrm{mg} / \mathrm{ml})$

(' $\mathrm{k}$ ' is an empirically derived constant relating height to muscle mass, values for which are given in table $1)$.

Table 1

Values for ' $k$ ' when plasma creatinine is in $\mathbf{m g} / \mathbf{d l}$

\begin{tabular}{|l|l|}
\hline \multicolumn{1}{|c|}{ Age } & k value \\
\hline Preterm neonates & 0.27 \\
\hline Term neonates & 0.37 \\
\hline Normal infants 0-18 months & 0.45 \\
\hline Boys, Girls 2-12 years & 0.55 \\
\hline Girls 13 -21 years & 0.55 \\
\hline Boys 13-21 years & 0.70 \\
\hline
\end{tabular}

GFR can be calculated by using the standard formula, which requires a 24 hour urine collection.
This does not improve the estimate of GFR over that calculated by Schwartz formula or other prediction equations. In addition, collection of 24 hour urine samples are difficult and unreliable in children. Methods to estimate GFR and assess markers of kidney damage are not completely sensitive or specific in detecting decreased GFR and kidney damage, respectively. Thus, clinicians should carefully consider all aspects of the patient's clinical presentation in interpreting test results and determining evaluation and management. Normal GFRs for children and young adults are shown in table 2 .

Table 2

Normal GFR for children and young adults ${ }^{1}$

\begin{tabular}{|c|c|}
\hline Age (Sex) & $\begin{array}{l}\text { Mean GFR } \pm \text { SD } \\
\left(\mathrm{ml} / \mathrm{min} / 1.73 \mathrm{~m}^{2}\right)\end{array}$ \\
\hline $\begin{array}{l}1 \text { week (males and } \\
\text { females) }\end{array}$ & $40.6 \pm 14.8$ \\
\hline $\begin{array}{l}2-8 \text { weeks (males and } \\
\text { females) }\end{array}$ & $65.8 \pm 24.8$ \\
\hline $\begin{array}{l}>8 \text { weeks (males and } \\
\text { females) }\end{array}$ & $95.7 \pm 21.7$ \\
\hline $\begin{array}{l}2-12 \text { years (males and } \\
\text { females) }\end{array}$ & $133.0 \pm 27.0$ \\
\hline $13-21$ years (males) & $140.0 \pm 30.0$ \\
\hline $13-21$ years (females) & $126.0 \pm 22.0$ \\
\hline
\end{tabular}

\section{Stages of CKD ${ }^{1}$}

CKD can be divided into five stages based on the level of GFR. This classification proposed by the National Kidney Foundation is likely to standardize definitions and categorization of patients worldwide. It is shown in table 3 .

Table 3

K/DOQI Classification of CKD : A Clininal action plan ${ }^{1,2}$

\begin{tabular}{|c|c|c|c|}
\hline Stage & Description & $\begin{array}{c}\text { GFR } \\
\left(\mathrm{ml} / \mathrm{min} / 1.73 \mathrm{~m}^{2}\right)\end{array}$ & Action \\
\hline 1 & $\begin{array}{c}\text { Kidney damage } \\
\text { with normal or } \\
\uparrow \text { GFR }\end{array}$ & $\geq 90$ & $\begin{array}{c}\text { Diagnosis and treatment, } \\
\text { Treatment of co-morbid conditions } \\
\text { Slow progression }\end{array}$ \\
\hline 2 & $\begin{array}{l}\text { Kidney damage } \\
\text { with mild } \downarrow \text { GFR }\end{array}$ & $89-60$ & Estimating progression \\
\hline 3 & Moderate $\downarrow$ GFR & $30-59$ & $\begin{array}{c}\text { Evaluating and treating } \\
\text { complications } \\
\end{array}$ \\
\hline 4 & Severe $\downarrow$ GFR & $15-29$ & Preparation for kidney replacement therapy \\
\hline 5 & Kidney failure & $<15$ & Replacement (if uraemia present) \\
\hline
\end{tabular}




\section{Complications related to level of renal function}

Many of the complications of CKD may be prevented or delayed by early detection and treatment. Growth retardation, hypertension, anaemia, uraemia, disorders of calcium and phosphate metabolism, renal osteodystrophy, metabolic acidosis, cardiovascular and neurological abnormalities are the major complications resulting from impaired kidney function.

\section{Measurements to assess complications of CKD}

Measurements that should be done to assess complications of CKD include growth parameters (height/supine length, weight and head circumference), pubertal status in older children, haematological investigations (full blood count and blood picture), biochemical investigations (urea, creatinine, calcium, phosphate, alkaline phosphatase, total proteins, serum albumin, blood $\mathrm{pH}$ and serum bicarbonate), parathyroid hormone assay, urine examination for proteins and deposits and culture, ECG, chest x-ray and ECHO cardiography to assess left ventricular hypertrophy and x-ray left wrist for bone age and evidence of osteodystrophy.

\section{Co-morbid conditions}

Identifying and managing co-morbid conditions will result in the improvement of function and well-being. Co-morbidity is defined as conditions that exist separate from those in CKD, which is the primary disease. Two types of co-morbid conditions should be considered:
A) diseases causing CKD
B) diseases unrelated to CKD

Obstructive uropathy, glomerulonephritis and diabetes mellitus are some of the examples for type A while chronic asthma, juvenile chronic arthritis are examples for type B.

\section{Risk of progression to end stage renal disease ${ }^{5}$}

Regardless of the aetiology, once there is a critical loss of nephron mass, the progression to renal failure is inevitable. As a significant proportion of nephrons are damaged, the remaining compensate for the loss of renal function. These nephrons undergo progressive hyperfusion and hyperfiltration that gradually causes increasing glomerular injury and sclerosis. As GFR decreases, there is increase in serum creatinine and the reciprocal of serum creatinine decreases with time in a relatively linear manner. The rate of progression, however, varies in different individuals and diseases, being faster in patients with heavy proteinuria and hypertension.

Strict blood pressure control and angiotensin converting enzyme inhibition or angiotensin receptor blockade are interventions that have been proven to be effective in slowing the progression of CKD. The effect of strict dietary control of protein in slowing progression is inconclusive.

Attempts should be made to prevent and correct the causes of acute decline in GFR which include, volume depletion, intravenous radiographic contrast, nephrotoxic drugs (aminoglycosides, cyclosporin, tacrolimus), nonsteroidal anti inflammatory drugs including cyclo-oxygenase type 2 inhibitors, obstruction of the urinary tract and infections.

Measurement of GFR should be obtained at least yearly in patients with CKD and more frequently in patients with $\mathrm{GFR}<60 \mathrm{ml} / \mathrm{min} / 1.73 \mathrm{~m}^{2}$ having risk factors for faster progression.

\section{Management of CKD should include}

1) Specific therapy, based on diagnosis

2) Prevention and treatment of complications

3) Evaluation and management of co-morbid conditions

4) Slowing the loss of kidney function

5) Preparation for end stage renal failure and renal replacement therapy

6) Replacement of kidney function by dialysis and transplantation

The following points need to be considered at each clinic visit.

\section{Nutrition $^{6}$}

Untreated, renal failure results in malnutrition and growth retardation in children. The goal of dietary management is the maintenance of nutritional status while minimizing symptoms due to accumulation of toxic products. Carefully supplemented nutritional therapy can ameliorate the effects of renal failure and promote improved well-being and growth. It may play a role in slowing the progression to renal failure. The services of a skilled paediatric renal dietician are invaluable to provide individualized nutritional therapy without disruption to the family's eating habits.

It is important to provide the recommended daily allowance (RDA) of protein appropriate for age and weight. Proteins of high biological value should be 
offered. The benefit of a low protein diet in retarding the deterioration of renal function has not been fully established in children.

Energy intake should be appropriate for age and weight $(100 \%$ RDA). In children with malnutrition calorie intakes up to $120 \%$ of RDA may be needed. In order to achieve this, most children with CRF require calorie supplements in the form of glucose polymers or fat emulsions. In infants and young children it may be necessary to deliver feeds by a nasogastric tube or gastrostomy tube.

Vitamin supplements are used routinely. Vitamin A and excessive use of Vitamin $\mathrm{C}$ should be avoided. The latter can cause oxalate deposition in the kidneys and further deterioration of renal function. Dairy products, chocolate and dark coloured sodas should be avoided to reduce the phosphate level. Food should be attractive, pleasant and unnecessary restrictions should be avoided

\section{Growth $^{7}$}

Growth is a sensitive indicator of the adequacy of CRF treatment. Height or supine length, weight and for children under 2 years of age head circumference should be measured at each clinic visit and values plotted for chronological age on appropriate charts. In case of poor growth, the protein and calorie intake should be assessed. Acidosis, salt depletion and calcium and vitamin deficiency should be corrected. If, despite optimal management, growth remains poor, i.e. the child's height velocity SDS is below -2 or the height SDS is below -2 , a trial of growth hormone (GH) therapy should be considered.

The dose of GH is $0.05 \mathrm{mg} / \mathrm{kg} /$ day 6-7 days a week. The high cost limits its wider use. Side effects include hyperglycaemia, enhanced skeletal maturation, benign intracranial hypertension and a theoretical risk of malignancy.

\section{Fluid and electrolyte balance}

Clinical assessment of child's state of hydration should be performed at each clinic visit. Children with CKD are able to maintain water and sodium balance until terminal renal failure. Many causes of CKD in children are associated with sodium loss, e.g. obstructive uropathy, renal dysplasia and juvenile nephronopthiasis. Sodium depletion results in contraction of extracellular volume and further impairment of renal function. It is also detrimental to growth. Some infants require sodium chloride 4-6 $\mathrm{mmol} / \mathrm{kg} /$ day to ensure physical and intellectual development. Sodium is restricted in children with hypertension. Water intake is determined by the child and should be offered freely to infants to satisfy thirst.

Most children with CKD are able to maintain potassium homeostasis satisfactorily. Potassium is restricted if GFR is less than $10 \mathrm{ml} / \mathrm{min} / 1.73 \mathrm{~m}^{2}$. If hyperkalaemia occurs, avoid ACE inhibitors, correct metabolic acidosis and treat with potassium exchange resins.

\section{Acid base status}

Maintenance of acid-base balance is extremely important in infants and children. Persistent metabolic acidosis is associated with failure to thrive in infancy and contributes to muscle degeneration, demineralisation of bone and hyperkalaemia.

Mild acidosis may not require correction. If serum bicarbonate level is less than $15 \mathrm{mEq} / \mathrm{L}$ oral supplementation of sodium bicarbonate is necessary. A starting dose of $2 \mathrm{mmol} / \mathrm{kg} / \mathrm{day}$ is frequently required and dosage adjusted according to the venous blood gas determinations to maintain a serum bicarbonate level around $20 \mathrm{mmol} / \mathrm{l}$.

\section{Anaemia $^{8}$}

Anaemia usually develops during the course of CKD and may be associated with adverse outcomes. Erythropoietin deficiency is the primary cause of anaemia in CKD. Other causes include functional or absolute iron deficiency, blood loss either occult or overt, bone marrow suppression, particularly by PTH and uraemic toxins, reduced half life of circulating blood cells and deficiencies of folate or vitamin $B_{12}$. In addition patients with CKD may have concurrent underlying haematological problems that contribute to anaemia.

A majority of patients with $\mathrm{CKD}$ can maintain satisfactory $\mathrm{Hb}$ levels, provided careful attention is paid to nutrition, iron, folic acid and $\mathrm{B}_{12}$ status and suppression of secondary hyperparathyroidism. If, despite these measures, a child's quality of life is being limited by anaemia, recombinant human erythropoietin (rHuEPO) should be commenced with a dose of 50 units $/ \mathrm{kg}$ given subcutaneously, twice a week and the dose adjusted according to the response to achieve a target haemoglobin level of $10-12 \mathrm{gm} / \mathrm{dl}$. The serum ferritin level should be maintained above $100 \mu \mathrm{g} / \mathrm{l}$ to ensure adequate iron supplies. 
Novel erythropoietic stimulatory proteins (NESP) are the latest in a new generation of long acting erythropoietin proteins that have a safety profile similar to EPO and are likely to be used extensively.

Blood transfusions should be avoided unless absolutely necessary as this may result in allosensitisation preventing them from receiving a successful transplantation. Leucocyte depleted blood should be used if possible and packed cells should be infused slowly under careful monitoring.

\section{Renal osteodystrophy ${ }^{9}$}

Manifestations of renal osteodystrophy include osteitis fibrosa cystica, the osseous consequence of hyperparathyroidism and rickets which is due to deficiency of $1,25(\mathrm{OH})_{2}$ cholecalciferol. More often, a mixed picture is seen.

Hyperparathyroidim is an important contributor to the development of skeletal abnormalities. Hyperphosphataemia, which is present at GFR levels below $80 \mathrm{ml} / \mathrm{min} / 1.73 \mathrm{~m}^{2}$, is the chief stimulus for the secretion of parathyroid hormone (PTH). Phosphate regulates $\mathrm{PTH}$, independent of its effects on serum calcium and 1,25 $(\mathrm{OH})_{2}$ cholecalciferol.

Control of plasma phosphate is therefore the most important factor in the prevention and control of hyperparathyroidism. This is achieved by reducing the dietary phosphate intake and by the use of calcium containing phosphate binders e.g. calcium carbonate, calcium acetate, which should be prescribed along with meals. The usual starting dose is $50-60 \mathrm{mg} / \mathrm{kg} /$ day of calcium. If taken on an empty stomach, the calcium salts act as a source of calcium. Aluminium containing phosphate binders should not be prescribed since aluminium toxicity can lead to neurological dysfunction and bone marrow suppression. Recently a non-calcium /non aluminium containing polymer, sevelamer has been introduced.

If however, PTH remains elevated, in spite of measures taken to reduce phosphates and with a normal plasma phosphate level, a vitamin D analogue should be prescribed. One alpha hydroxycholecalciferol, 15-30ng/kg/once daily, is recommended. It is important to monitor the calcium levels in children treated with one alpha cholecalciferol to avoid hypercalcaemia and metastatic calcification.

Plasma calcium, phosphate and alkaline phosphatase are measured each time the child is seen and PTH should be checked regularly and therapy adjusted accordingly. Annual x-ray of the left hand is done to assess the bone age and evidence of rickets.

\section{Hypertension}

Control of hypertension improves renal function and slows progression to end stage renal disease (ESRD). The blood pressure can often be restored to normalcy by salt and water restriction. If these measures fail to control the BP, antihypertensive drugs should be used. The most commonly used drugs are calcium channel blockers, ACE inhibitors and alpha and betablockers. In patients with fluid overload, diuretics may be used.

\section{Infections}

Underlying urinary tract anomalies predispose patients with CKD to recurrent urinary tract infections. A sample of urine should be cultured if they are symptomatic and they should be maintained on low-dose prophylactic antibiotics. It is important to note that nitrofurantoin becomes less effective with declining renal function. The patients with $\mathrm{CKD}$ are at risk of developing other infections as a result of immunosuppression. These should be detected and treated promptly to reverse catabolism.

\section{Bleeding diathesis}

Platelet dysfunction leading to increased risk of bleeding is seen in many patients with advanced CKD. Dialysis, blood transfusion, desmopressin (DDAVP) infusion are used to correct platelet dysfunction. Prior to renal biopsy or operative procedures DDAVP infusion can be given if bleeding time is prolonged.

\section{Acute deterioration of GFR}

Acute deterioration of renal function results from dehydration, urinary tract infection, uncontrolled hypertension and acute obstruction. These should be recognised promptly and treated.

\section{End stage renal disease}

ESRD is defined as GFR $<15 \mathrm{ml} / \mathrm{min} / 1.73 \mathrm{~m}^{2}$ or a decline in renal function to an extent that life threatening biochemical abnormalities persist despite optimal medical management. Such patients require renal replacement therapy (RRT) in the form of maintenance dialysis or transplantation.

It is important that the child and the family understand the rationale of CKD therapy and that 
ultimately RRT will be necessary. It is possible to predict with reasonable accuracy when ESRD will supervene from a plot of the reciprocal of plasma creatinine or the calculated GFR. Using this prediction there should be a full discussion at an appropriate time on the various RRT options available. It is very helpful for the child and family to meet other children treated by peritoneal or haemodialysis and also those who have been transplanted.

If a child is scheduled for a renal transplantation, the immunisations including hepatitis B and, if indicated, varicella-zoster should be completed at least 3 months before transplantation is anticipated. Children with associated bladder dysfunction require very careful assessment, including urodynamic studies, to ensure that the bladder is safe for transplantation. Management with clean intermittent catheterisation and/or bladder augmentation surgery may be necessary to achieve this. Drugs that induce hepatic enzymes should be replaced with non enzyme inducing drugs prior to transplantation to improve the efficacy of post transplant immunosuppressive therapy.

\section{Social and psychological support}

Management of a child with progressive CKD can be extremely stressful even to the best adjusted families. CKD and its treatment may be disruptive to the child's schooling, social life and family life. There may be financial difficulties as a result of a parent having to give up work and the expense of travelling including travelling long distances to a specialist centre. Siblings may feel excluded and the relationship between parents is under stress.

All families should have easy access to a social worker for help with practical and financial difficulties as well as for psychological support. Ideally a child psychologist or a psychiatrist should be a part of the team involved in the management of these children

With careful attention given to the management points detailed above, it is possible to improve the well being, activity and growth of children with CKD and possibly delay the time for RRT requirements. ${ }^{10}$

\section{References:}

1. National Kidney Foundation. K/DOQI Clinical practice guidelines for chronic kidney disease: evaluation, classification and stratification. $\mathrm{Am} \mathrm{J}$ Kidney Dis 2002; 39(2 Suppl 1): 1-266

2. Hogg RS, Furth S, Lemly KV, et al. National Kidney Foundation's Kidney Disease Outcomes Quality Initiative. Clinical Practice Guidelines for kidney disease in children and adolescents. Paediatrics 2003; 111:1416-21.

3. Moudgil A, Bagga A. Evaluation and treatment of chronic renal failure. Indian J Paediatr 1999; 66:241-53.

4. Schwartz GJ, Brion LP, Spitzer A. The use of plasma creatinine concentration for estimating glomerular filtration rate in infants, children and adolescents. Pediatr Clin North Am 1987; 34:571-90

5. Schena FP, Gesualdo L, Grandaliano G, et al. Progression of kidney damage in human glomerulornephritis. Kidney Int 1997;52:143957.

6. Klahr S, Levey AS, Beck GJ et al. For the modification of diet in Renal Disease Study Group: The effects of dietary protein restriction and blood pressure control on the progression of chronic renal failure. $N$ Engl $J$ med 1994; 330: 877-84.

7. Rizzoni G, Baso T, Setari M, Growth in children in chronic renal failure. Kidney Int 2000;57: 1681-7.

8. Van Damme-Lombaerts R, Herman J. Erythropoietin treatment in children with renal failure. Pediatr Nephrol 2000; 13: 148-52

9. Ridgen SPA. The treatment of renal osteodystrophy. Paediatr Nephrol 1996;10:653-5

10. Ridgen SPA. The management of chronic and end stage renal failure in children. In: Webb N, Postlethwait R, (Eds). Clinical Paediatric Nephrology, $3^{\text {rd }}$ ed. Oxford: Oxford University Press.2003; 427-45 